\title{
Three-Stage Six-Step Flue-Curing Technology for Viginia Tobacco Leaves and Its Application in China
}

\author{
Hongfeng Wang, Houlong Jiang, Chen Xu, Daibin Wang, Chao Yang and Bojun Wang \\ Chongqing Tobacco Science Research Institute, Chongqing 400715, China
}

\begin{abstract}
In order to overcome the problem that the leaf yellowing stage in tobacco curing reduces the fragrance of the product, this study introduced the principle and key parameters of a three-stage six-step curing technology. The field trail was conducted in Wulong county of Chongqing city in 2010, and Virginia K326 was the tested cultivar. The middle leaves were harvested and plaited after maturity, and then cured with the three-stage six-step curing technology and traditional three-stage curing technology, respectively. Three replicates were established for each of the two curing technologies. Then, chemical constituents, aromatic substances and smoking quality were analyzed. The results show that compared with the traditional three-stage curing technology, the three-stage six-step curing technology produces more suitable ratios of chemical constituents, higher aromatic component content and higher smoking quality grade of tobacco leaves. Therefore, the continuous improvement of corollary equipment and matching technologies is expected to widen the applications of the three-stage six-step curing technology in tobacco and provide a strong technical support for the development of the tobacco industry.
\end{abstract}

Key words: Flue-cured tobacco, curing technology, quality index.

\section{Introduction}

With the construction of bulk curing barns and the reconstruction of ordinary curing barns in recent years, bulk curing barns have served as important curing devices in the main tobacco-producing regions of China. These curing barns not only save energy, labor, and cost, but also significantly improve the quality grade of tobacco leaves [1]. However, the extension of bulk curing barns has reduced the oil content, maturity, aroma and taste of flue-cured tobacco leaves [2, 3]. Thus, an improved technology for bulk curing barns is crucial to enhance the quality of tobacco leaves and increase the income of tobacco farmers. With the development of the tobacco industry, curing technologies have constantly been improved to adapt to climate characteristics and tobacco leaf conditions in different regions. For examples, a three-stage curing method was proposed in Henan province in the early 1980s, a low-temperature, low-humidity curing

Corresponding author: $\mathrm{Chen} \mathrm{Xu}$, $\mathrm{Ph} . \mathrm{D}$., research fields: tobacco cultivation, physiology and biochemistry. method in Yunnan province in 1987 [4], a seven-step curing method in Guizhou province in 2014 [5], and a five-step curing method in Jiangxi province in 1997 [6]. Some researchers improve the quality of tobacco leaves, increase the ratio of middle- and high-grade tobacco and upgrade the income of tobacco farmers by adjusting the parameters of the three-stage curing technology; these parameters include fan speed [7], temperature and humidity [8], heating rate [9] and duration at a stable temperature [10, 11]. Recent studies on the quality problems of tobacco leaves during the popularization of bulk curing barns have mainly focused on the construction of curing barns. Studies have rarely focused on tobacco curing effects being improved by the local adjustment of curing operation, although a few systematic studies have explored the suitability of different curing processes for bulk curing barns. Accordingly, the paper systematically studied the heating rate, fan speed and optimal duration at critical temperature points of 36 , $38,41-43,45-47,52-54$ and $65-68{ }^{\circ} \mathrm{C}$ to help optimize the curing process in bulk curing barns and provide a 
theoretical basis for scientific tobacco curing.

\section{Materials and Methods}

\subsection{Experimental Materials}

Field trail was conducted in Wulong county of Chongqing city in 2010, and Virginia K326 was the tested cultivar. The test field had weakly acidic moderate loamy soil and flat terrain with continuous tobacco cropping. The tobacco leaves grew well under routine field management, and the middle leaves were harvested and plaited after maturity. Some tobacco leaves were cured in strict accordance with the three-stage six-step curing technology in the horizontal bulk curing barns in Lutang Factory in Wulong county. The remaining leaves (control) were cured in strict accordance with the traditional three-stage curing technology. Three replicates were established for each of the two curing technologies. Samples of C2F tobacco leaves grade were analyzed after curing.

\subsection{Three-Stage Six-Step Curing Technology}

On the basis of the various moisture levels, pigment contents, starch contents, protein contents and enzyme activities in tobacco leaves, the traditional three-stage curing technology was subdivided into the following six steps [12]: preprocessing, leaf yellowing, branch vein yellowing, main vein yellowing, aromatic substance synthesis and stem drying (Fig. 1). To improve the curing effect, a variable-frequency fan was adopted, and factors, such as, temperature, humidity, duration at some critical temperature points and fan speed, were completely coupled in accordance with the theories of moisture removal by external power (water potential difference), critical yellowing value and "gold curing period." Thus, the leaves can be completely yellowed during curing, with sufficient substance decomposition and synthesis in the leaves to satisfy the requirements on tobacco color and fragrance. The process parameters at the different curing stages are described below.

\subsubsection{Tobacco Preprocessing}

At this stage, the equilibrium of temperature and humidity was required to prepare for the leaf yellowing stage. After ignition, the ceiling dry-bulb temperature increased from $35{ }^{\circ} \mathrm{C}$ to $36{ }^{\circ} \mathrm{C}$ at a rate of $2{ }^{\circ} \mathrm{C} / \mathrm{h}$. The wet-bulb temperature was maintained at $34 \pm 0.5{ }^{\circ} \mathrm{C}$ for approximately $8-12 \mathrm{~h}$. This stage was completed when the auricles of tobacco leaves in the ceiling turned yellow and the yellowing degree of leaves reached approximately $50 \%-60 \%$.

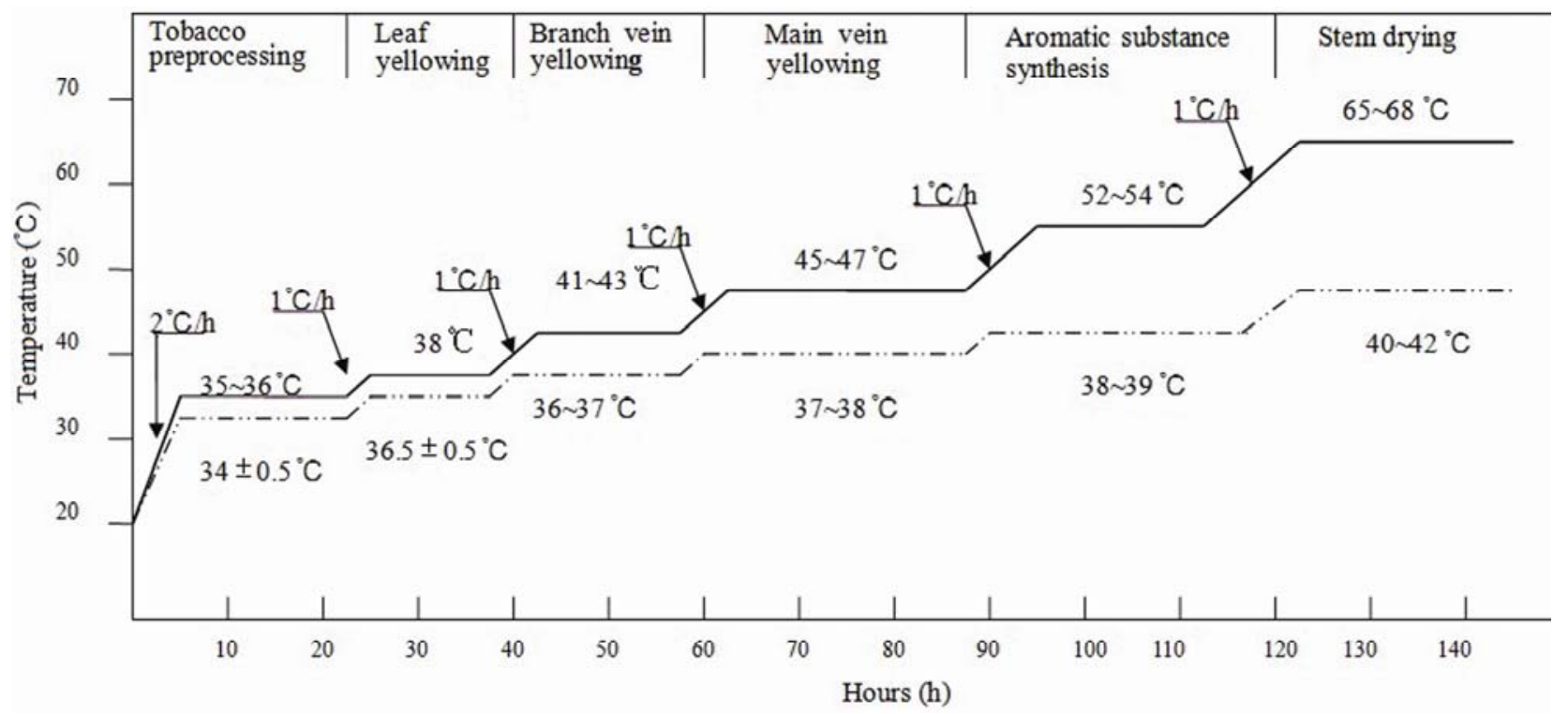

Fig. 1 The operating technology curve of three-stage six-step curing of flue-cured tobacco. 


\subsubsection{Leaf Yellowing}

The main task in this stage was to achieve leaf yellowing. After preprocessing, the ceiling dry-bulb temperature increased from $35-36{ }^{\circ} \mathrm{C}$ to $38^{\circ} \mathrm{C}$ at a rate of $1{ }^{\circ} \mathrm{C} / \mathrm{h}$. The wet-bulb temperature was stabilized at $36 \pm 0.5{ }^{\circ} \mathrm{C}$ for approximately $12-24 \mathrm{~h}$. This stage was completed when the tobacco leaves in the ceiling turned yellow, with the veins remaining green.

\subsubsection{Branch Vein Yellowing}

The critical point of yellowing in tobacco leaves appeared at this stage. This stage aimed to achieve the yellowing of branch veins, the sufficient degradation of macromolecular substances and the increased degree of leaf vertical shrinkage. Meanwhile, the generation of smooth rigid leaves and green tobacco should be reduced and avoided. In specific, the dry-bulb temperature increased from $38{ }^{\circ} \mathrm{C}$ to 41-43 ${ }^{\circ} \mathrm{C}$, whereas the wet-bulb temperature was stabilized at $36-37{ }^{\circ} \mathrm{C}$ for approximately 8-20 h. The stage was completed when the tobacco leaves in the ceiling were completely yellowed, except for the main veins.

\subsubsection{Main Vein Yellowing}

This stage was the "gold curing period" of tobacco leaves. This stage aimed to achieve the yellowing of main veins, the sufficient degradation of macromolecular substances, the accumulation of aroma precursors, the increased degree of leaf horizontal shrinkage and the improved maturity and oil content of tobacco leaves. After the complete yellowing of leaves and branch veins, the dry-bulb temperature increased from $41-43{ }^{\circ} \mathrm{C}$ to $45-47{ }^{\circ} \mathrm{C}$ at a rate of $1{ }^{\circ} \mathrm{C} / \mathrm{h}$, and the wet-bulb temperature was maintained at $37-38{ }^{\circ} \mathrm{C}$ for $12-24 \mathrm{~h}$. This stage was completed when the stems of the leaves in the ceiling turned white and the leaves slightly curled.

\subsubsection{Aromatic Substance Synthesis}

This stage was critical to the synthesis of aromatic substances in tobacco leaves. The main task was to increase the aromatic substance content and decrease the color difference between the front and back of leaves. After the yellowing of main veins, the dry-bulb temperature increased from $45-47{ }^{\circ} \mathrm{C}$ to $52-54{ }^{\circ} \mathrm{C}$, and the wet-bulb temperature was maintained at $38-39{ }^{\circ} \mathrm{C}$ for $12-20 \mathrm{~h}$. This stage was completed when all the tobacco leaves were obviously curled and the color difference between the front and back of leaves decreased.

\subsubsection{Stem Drying}

The main task at this stage was to dry the leaves and stems, and decrease the volatilization of aromatic substances. When all the tobacco leaves reached an obvious curling state, the dry-bulb temperature increased from $52-54{ }^{\circ} \mathrm{C}$ to $60{ }^{\circ} \mathrm{C}$ at a rate of $1{ }^{\circ} \mathrm{C} / \mathrm{h}$, and the wet-bulb temperature was stabilized at $40{ }^{\circ} \mathrm{C}$. The color difference between the front and back of leaves gradually decreased. Subsequently, the dry-bulb temperature increased to $65-68{ }^{\circ} \mathrm{C}$ at a rate of $1{ }^{\circ} \mathrm{C} / \mathrm{h}$, whereas the wet-bulb temperature was stabilized at $41-42{ }^{\circ} \mathrm{C}$. Curing was terminated when the main veins of more than $95 \%$ leaves were parched.

Much attention should be given to the following points when operating the three-stage six-step curing technology: (1) the duration at $41-42{ }^{\circ} \mathrm{C}$ and $52-54{ }^{\circ} \mathrm{C}$ should be extended appropriately, whereas that at 35-36 ${ }^{\circ} \mathrm{C}$ and $65-68{ }^{\circ} \mathrm{C}$ should be short; (2) the dry-bulb temperature should not exceed $35{ }^{\circ} \mathrm{C}$ and $68{ }^{\circ} \mathrm{C}$ at the initial and stem-drying stages, respectively; (3) the wet-bulb temperature should not be lower than $35^{\circ} \mathrm{C}$ and $37^{\circ} \mathrm{C}$ at the branch vein yellowing and aromatic substance synthesis stages, respectively; (4) the dry-bulb temperature should always increase slowly, whereas the wet-bulb temperature should be stabilized at a certain range; (5) the dry-bulb temperature should remain steady at the constant temperature stage; (6) the duration at a certain temperature at each stage should be determined in accordance with the specific condition of tobacco leaves.

\subsection{Determination Method}

Chemical constituents were analyzed using the 

and Its Application in China

corresponding methods. Total sugar (TS) and reducing sugar (RS) contents were determined according to the method described by Li [13]. Nicotine (Nic.) was determined as described by Xiao [14]. Total nitrogen (TN) was measured using the Kjeldahl method [15]. Protein content and petroleum ether substances (PES) were measured as described by Alexander et al. [16] and Wang [17], respectively. The contents were expressed as percentage. Starch content was measured by Association of Official Analytical Chemists (AOAC) [18]. The TS/Nic. and TN/Nic. ratios were also measured.

Neutral aroma components were extracted using methylene chloride after steam distillation. The extracted components were analyzed via gas chromatography-mass spectrometry (GC-MS) and identified in the National Institute of Standards and Technology (NIST) library. The tobacco leaf samples were qualitatively analyzed using the HP5890II-5972 GS/MS system (US). The chromatographic column was HP-5 with a size of $60 \mathrm{~m} \times 0.25 \mathrm{~mm}$ (inner diameter) $\times 0.25 \mu \mathrm{m}$ (film thickness dimension). The flow rate of carrier gas $(\mathrm{He})$ was $8.0 \mathrm{~mL} / \mathrm{min}$. The inlet, transmission and ion source temperatures were $250{ }^{\circ} \mathrm{C}, 280{ }^{\circ} \mathrm{C}$ and $170{ }^{\circ} \mathrm{C}$, respectively. The temperature program comprised four phases: maintaining at $50{ }^{\circ} \mathrm{C}$ for $5 \mathrm{~min}$; increasing to $120{ }^{\circ} \mathrm{C}$ at a rate of $5{ }^{\circ} \mathrm{C} / \mathrm{min}$ and maintaining for $5 \mathrm{~min}$; increasing to $180{ }^{\circ} \mathrm{C}$ at a rate of $5{ }^{\circ} \mathrm{C} / \mathrm{min}$ and maintaining for $5 \mathrm{~min}$; and increasing to $250{ }^{\circ} \mathrm{C}$ at a rate of $6^{\circ} \mathrm{C} / \mathrm{min}$ and maintaining for $15 \mathrm{~min}$. The split ratio and injection volume were $1: 15$ and $2 \mathrm{~L}$, respectively. Ionization energy was $70 \mathrm{eV}$, and the ionization mode was electron ionization. The range of mass number was 50-500 Da. The components contained can be identified through retrieval in the NIST02 spectrum library. The relative correction factor was set as 1 , and the internal standard method was adopted for quantification.

\section{Results}

\subsection{Quantitative Analysis of Chemical Constituents}

Table 1 shows the effects of different curing technologies on the chemical constituents of tobacco leaves. Except for PES and TS/Nic., the chemical constituents of tobacco leaves cured by the three-stage six-step curing technology and traditional three-stage curing technology showed significant differences. The contents of nicotine, TN, RS, TS and starch were lower in the tobacco leaves cured by the three-stage six-step curing technology than that in those cured by the three-stage curing technology. The protein content was $18.18 \%$ lower, while the content of PES improved by $5.34 \%$ in the tobacco leaves cured by the three-stage six-step curing technology than that in those cured by the three-stage curing technology. The $\mathrm{TS} / \mathrm{Nic}$. and TN/Nic. ratios indicated that the chemical constituents of the tobacco leaves cured by the three-stage six-step curing technology were more compatible to one another and satisfied the requirement of high-quality tobacco leaves better than those of the tobacco leaves cured by the three-stage curing technology [17].

\subsection{Quantitative Analysis of Aromatic Substances}

The change in aromatic components is affected by

Table 1 Effects of different curing methods on the chemical constituent contents (\%) of tobacco leaf.

\begin{tabular}{llllllllll}
\hline \multirow{2}{*}{ Curing technology } & \multicolumn{7}{c}{ Chemical constituent contents (\%) } \\
\cline { 2 - 10 } & TS & RS & Nic. & TN & Starch & Protein & PES & TS/Nic. & TN/Nic. \\
\hline Three-stage six-step & $25.79^{\mathrm{a}}$ & $22.45^{\mathrm{a}}$ & $2.78^{\mathrm{a}}$ & $2.63^{\mathrm{a}}$ & $4.04^{\mathrm{a}}$ & $8.67^{\mathrm{a}}$ & $5.81^{\mathrm{a}}$ & $9.28^{\mathrm{a}}$ & $0.95^{\mathrm{a}}$ \\
Three-stage & $31.18^{\mathrm{b}}$ & $26.43^{\mathrm{b}}$ & $3.43^{\mathrm{b}}$ & $2.87^{\mathrm{b}}$ & $6.90^{\mathrm{b}}$ & $10.60^{\mathrm{b}}$ & $5.50^{\mathrm{a}}$ & $9.11^{\mathrm{a}}$ & $0.84^{\mathrm{b}}$ \\
\hline$F$ value & 259.226 & 27.126 & 68.429 & 8.180 & 25.196 & 6.135 & 0.241 & 0.500 & 9.075 \\
$P$ & 0.000 & 0.006 & 0.001 & 0.046 & 0.007 & 0.068 & 0.649 & 0.519 & 0.039 \\
\hline
\end{tabular}

Data with different letters are significantly different $(P<0.05$, Duncan's method $)$ in the same column. 
Table 2 Effects of different curing methods on the neutral aroma substance contents $(\mu \mathrm{g} / \mathrm{g})$ of tobacco leaf.

\begin{tabular}{llllllllll}
\hline \multirow{2}{*}{ Curing technology } & \multicolumn{7}{c}{ Neutral aroma substance $(\mu \mathrm{g} / \mathrm{g})$} \\
\cline { 2 - 9 } & Esters & Acids & Ketones & Alcohols & Aldehydes & Phenols & Heterocycles & Alkenes & Total \\
\hline Three-stage six-step & 17.949 & 39.731 & 52.981 & 29.642 & 6.262 & 2.476 & 4.734 & 955.591 & $1,109.366$ \\
Three-stage & 7.363 & 14.976 & 40.340 & 18.440 & 5.489 & 1.951 & 3.639 & 626.327 & 718.525 \\
\hline
\end{tabular}

Table 3 Effects of different curing methods on the smoking quality content of tobacco leaf.

\begin{tabular}{lllllllllll}
\hline Curing technology & $\begin{array}{l}\text { Aroma } \\
\text { quality }\end{array}$ & $\begin{array}{l}\text { Aroma } \\
\text { quantity }\end{array}$ & Odor & Density & Strength & Irritation & \multicolumn{2}{l}{$\begin{array}{l}\text { Lingering } \\
\text { smell }\end{array}$} & Combustibility $\begin{array}{l}\text { Ash } \\
\text { color }\end{array}$ & Total \\
\hline Three-stage six-step & $6.73^{\mathrm{a}}$ & $6.83^{\mathrm{a}}$ & $5.93^{\mathrm{a}}$ & $6.27^{\mathrm{a}}$ & $6.13^{\mathrm{a}}$ & $6.43^{\mathrm{a}}$ & $6.73^{\mathrm{a}}$ & $5.87^{\mathrm{a}}$ & $6.07^{\mathrm{a}}$ & $57.07^{\mathrm{a}}$ \\
Three-stage & $6.33^{\mathrm{b}}$ & $6.17^{\mathrm{b}}$ & $5.07^{\mathrm{b}}$ & $5.43^{\mathrm{b}}$ & $5.73^{\mathrm{b}}$ & $5.77^{\mathrm{b}}$ & $5.37^{\mathrm{b}}$ & $5.90^{\mathrm{a}}$ & $6.03^{\mathrm{a}}$ & $51.53^{\mathrm{b}}$ \\
\hline$F$ value & 3.064 & 1.471 & 3.485 & 10.081 & 2.571 & 1.613 & 17.153 & 0.25 & 0.091 & 57.528 \\
$P$ & 0.155 & 0.292 & 0.135 & 0.034 & 0.184 & 0.273 & 0.014 & 0.643 & 0.778 & 0.002 \\
\hline
\end{tabular}

Data with different letters are significantly different $(P<0.05$, Duncan's method) in the same column.

The scores of smoking quality were given by smoking expert.

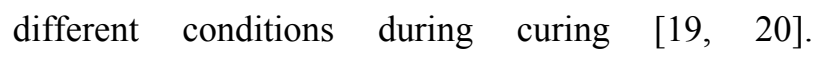
High-quality tobacco leaves with well-balanced constituents can be cured, only when factors, such as temperature, humidity, duration at a certain temperature and fan speed, match one another. The aromatic substance contents of the tobacco leaves cured by the two types of curing technologies were compared in Table 2. A total of 76 types of neutral aromatic substances were divided into eight categories: esters, acids, ketones, alcohols, aldehydes, phenols, alkenes and heterocycles. The contents of the eight aromatic substances were higher in the tobacco leaves cured by the three-stage six-step curing technology than that in those cured by the three-stage curing technology. The total content of aromatic substances was $54.39 \%$ higher in the tobacco leaves cured by the three-stage six-step curing technology than that in those cured by the three-stage curing technology.

\subsection{Analysis of Smoking Quality}

The smoking quality indicators (excluding the combustibility and ash color) of the tobacco leaves cured by the three-stage six-step curing technology were conspicuously higher than those of the tobacco leaves cured by the three-stage curing technology (Table 3). The tobacco leaves cured by the three-stage six-step curing technology smelled refreshing, delicate, and mellow, with abundant aroma and less odor. Moreover, both the density and strength were moderate with minimal irritation. The combustibility was favorable, and the ash was white. The general score was increased by $10.75 \%$. In particular, the aroma quality, odor, density, irritation and lingering smell were significantly improved by $6.32 \%, 16.96 \%$, $15.47 \%, 11.44 \%$, and $25.33 \%$, respectively. The scores of the remaining indicators were higher in the tobacco leaves cured by the three-stage six-step curing technology than that in those cured by the three-stage curing technology. As an exception, the combustibility and ash color had similar scores in the two groups. These results indicate that the three-stage six-step curing process can significantly enhance the smoking quality of tobacco leaves.

\section{Discussion}

The effects of three-stage six-step curing technology and three-stage curing technology on the quality of tobacco leaves were evaluated using horizontal bulk curing barns. The chemical compositions (excluding PES and TS/Nic. ratio) of the tobacco leaves cured by the two methods significantly differed. The contents of carbohydrates (RS and TS), TN, nicotine and total starch were lower in the tobacco leaves processed by the three-stage six-step curing technology than that in those cured by the three-stage curing technology. This result may be attributed to the longer curing time in the new method than that in the conventional method. In this process, 
the starch decomposition was almost thorough, with no further increase in RS content [21]. Meanwhile, the carbohydrates were continuously consumed by respiration. Moreover, prolonged curing time allowed the starch, proteins and other macromolecules in the tobacco leaves to be decomposed thoroughly [22] and thus significantly increased the content of petroleum ether [23]. In general, the three-stage six-step curing technology had a more significant effect on the chemical composition of tobacco leaves and satisfied the chemical substance requirements of high-quality tobacco leaves better than the three-stage curing technology. The contents of esters, acids, ketones, alcohols, aldehydes, phenols, alkenes and heterocycles were higher in the tobacco leaves processed by the three-stage six-step curing technology than that in those processed by the three-stage curing technology. In addition, the total content of aromatic substances increased by $35.23 \%$ with the new method. This increase is mainly caused by the three-stage six-step curing technology properly extending the duration at several vital temperature ranges, thereby allowing the complete degradation of macromolecules into many aromatic substances $[10,11,24,25]$. The analysis of smoking quality showed that the tobacco leaves cured by the three-stage six-step curing technology smelled refreshing, delicate and mellow, with abundant aroma and less odor. The density and strength were both moderate with minimal irritation. The tobacco leaves had favorable combustibility and white ash, and the general score of smoking quality was apparently superior. The critical curing period in the three-stage six-step curing process was extended, which enabled the chemical composition to have appropriate content and good coordination; the aromatic substance content was also high. Hence, the smoking quality is relatively high [26].

\section{Conclusions}

The three-stage six-step curing technology coordinates well the temperature and humidity conditions, duration at vital curing points, heating rate and fan speed with consideration of the condition of tobacco leaves and change degree during curing. Thus, the curing process is scientifically divided into six steps. With this curing technology, the chemical composition of tobacco leaves is appropriate, and the constituents are compatible with one another. Meanwhile, the aroma quality and volume are significantly improved and the smoking quality is considerably enhanced. Currently, the Chongqing tobacco-producing region widely promotes this curing technology, which considerably reduces the possibility of flue-cured tobacco being greenish, greyish, stiff, short in oil and poor in aroma quality. The three-stage six-step curing technology should be further improved. The constant improvement of facilities and processes is expected to widen the applications of this technology in tobacco curing and present a strong technical support for the development of the tobacco industry in Chongqing city.

\section{References}

[1] Sun, S. G., and Wang, J. 2011. "Effect of Different Bulk Baking Technologies on Leaf Quality of Flue-Cured Tobacco." Acta Agriculturate Jiangxi 23 (6): 37-9. (in Chinese)

[2] Wang, W. F., Chen, J. H., Song, C. P., and Gong, C. R. 2005. "The Research Progress on Bulk Curing Barn." Chinese Tobacco Science 26 (3): 12-4. (in Chinese)

[3] Dai, L., Huang, Y. C., Gong, C. R., Yu, J. H., and Yang, S. J. 2008. "Effects of Different Temperature and Humidity Yellowing Conditions on Aroma Constituents of Tobacco Leaves during Bulk Curing." Acta Agriculture Boreali-Sinica 23 (6): 148-52. (in Chinese)

[4] Zhang, Z. F. 1987. "Study on the Reformation of Curing Method of Flue-Cured Tobacco." Chinese Tobacco 9 (2): 36-9. (in Chinese)

[5] Wu, Y., Hou, J., Gou, J. Y., He, K., Huang, C. Y., and Tan, Z. D. 2014. "Study on the 'Seven Steps Method' Modes of Loose Leaves Bulk Curing of Zheng'an County." Journal of Anhui Agriculture Science 42 (28): 9916-9. (in Chinese)

[6] Liu, Q. Y., and He, K. X. 1997. "Comparison of the Effect of Five-Step Curing Method and Double Low Curing Method in Flue-Cured Tobacco." Jiangxi Agricultural Science \& Technology 46 (4): 19-21. (in 
Chinese)

[7] Zhan, J., He, F., Song, C. P., Li, W., Liu, C., and Gong, C. R. 2011. "Effects of Fan Speed during Leaf Drying and Stem Drying Stage of Bulk Curing on the Appearance Quality and Internal Quality of Upper Leaves in Flue-Cured Tobacco." Journal of Henna Agricultural University 45 (6): 617-23. (in Chinese)

[8] Zhan, J., Wu, S. J., He, F., Li, W., Huo, K. L., and Gong, C. R. 2011. "Effects of Temperature and Humility on the Appearance Quality and Internal Quality of Upper Leaves of Flue-Cured Tobacco in Stem-Drying Stage during Bulk Curing." Journal of Gansu Agricultural University 46 (6): 29-35. (in Chinese)

[9] Zhan, J., Li, W., Wang, T., Liu, J. J., He, F., and Gong, C. R. 2011. "Effect of Heating Rate during Leaf-Drying Stage of Bulk Curing on Smoking Quality of Upper Flue-Cured Tobacco Leaf." Acta Agriculture Universitatis Jiangxiensis 33 (5): 866-72. (in Chinese)

[10] Song, X. H., Liu, G. S., Fu, S. Y., and Zhang, C. H. 2010. "Effects of Prolonging the Time of Yellowing and Leaf Drying on Neutral Aroma Constituents of Tobacco Leaves during Curing." Acta Agriculture Zhejiangensis 22 (2): 249-52. (in Chinese)

[11] Zhou, H., Liu, G. S., Jiang, H. L., Xie, D. P., Xiao, J. G., and Li, Y. T. 2010. "Effects of Prolong Curing Time of Yellowing Stage on Petroleum Ether Extracts and Aroma Constituents and Non-volatile Organic Acid of Flue-Cured Tobacco Leaves." Journal of Henan Agricultural University 44 (6): 619-24. (in Chinese)

[12] Gong, C. R., Zhou, Y. H., and Yang, H. W. 2006. Introduction for Three Stages Curing of Flue-Cured Tobacco. Beijing: Science Press. (in Chinese)

[13] Li, H S. 2000. Principal and Techniques of Plant Physiological Biochemical Experiment. Beijing: Higher Education Press, 194-201. (in Chinese)

[14] Xiao, X. Z. 1997. Tobacco Chemistry. Beijing: China Agricultural Science and Technology Press. (in Chinese)

[15] Bremner, J. M., and Mulvaney, C. S. 1984. "Total Nitrogen.” In Methods of Soil Analysis: Part 2, Chemical and Microbiological Properties, 2nd ed., edited by Page, A. L. Madison, WI: American Society of Agronomy, 595-624.

[16] Alexander, R. R., Griffiths, J. M., and Wilkinson, M. L. 1989. Basic Biochemical Methods. New York: Wiley.
[17] Wang, R. X. 2003. Tobacco Chemistry. Beijing: China Agricultural Publishing. (in Chinese)

[18] Association of Official Analytical Chemists (AOAC). 1990. Official Methods of Analysis, 15th ed.. Washington, DC: AOAC.

[19] Zhang, F. S., Gong, C. R., Su, H. Y., Li, W., Zhan, J., Cheng, C. C., and Zhang, H., W. 2012. "Effects of Stable Temperature Time on Quality of Tobacco Leaves." Jiangsu Agricultural Sciences 40 (2): 218-21. (in Chinese)

[20] Zhao, H. W., Cui, G. M., Zhao, Y. Z., and Fan, H. E. 2011. "Gray Correlation Cluster Analysis of Wind Speed Index between Tobacco Leaves in Bulk Curing Barns." Journal of Southwest University 33 (11): 140-5. (in Chinese)

[21] Dong, Z. J., Chen, J. H., and Gong, C. 2000. "Study on Changes of Main Chemical Components in Flue-Cured Tobacco Leaf under Different Yellowing and Colour-Fixing Temperature." Chinese Tobacco Science 21 (3): 21-4. (in Chinese)

[22] Zuo, Q. B., Liu, G. S., Bi, Q. W., Wang, J., Wang, H. M., and Li, G. 2010. "Effects of Different Flue-Curing Techniques on Quality of Flue-Cured Tobacco in Enshi of Hubei Province." Acta Agriculture Jiangxi 22 (2): 33-5. (in Chinese)

[23] Jiang, H. L., Liu, G. S., Zhou, H., and Hu, H. C. 2012. "Effects of Yellowing and Color Fixing Durations during Curing on Chemical Components in Flue-Cured Tobacco Leaves.” Tobacco Science and Technology 45 (12): 33-8. (in Chinese)

[24] Gong, C. R., Gao, Y. Z., Wang, W. F., Liang, R. H., Liu, S. P., Liu, G., and Wei, Y. W. 2008. "Effects of Different Temperature and Humidity Yellowing Conditions on Neutral Aroma Constituents of Tobacco Leaves during Bulk Curing." Journal of Yunnan Agricultural University 23 (2): 215-9. (in Chinese)

[25] Wang, B. J., and Zhang, W. P. 2010. "Effects of Different Stable Time of Key Temperatures on Quality of Flue-Cured Tobacco Leaf in Bulk-Curing." Guangxi Agricultural Science 41 (12): 1329-31. (in Chinese)

[26] Zhan, J., Zhou, F. F., He, F., Wang, T., Li, W., Fan, S. J., and Gong, C. R. 2012. "Effects of Different Humidity during the Later Stage of Bulk Curing on Aroma Quality of Flue-Cured Tobacco Leaf." Journal of Southwest University 34 (3): 1-8. (in Chinese) 